DE82 009731

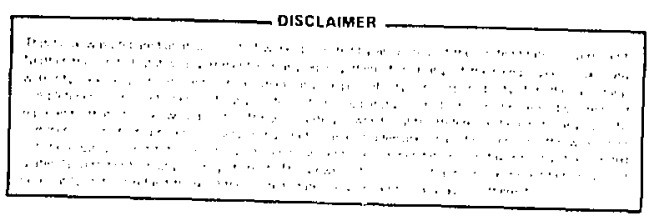

\title{
Spectrophotometric Determination of Plutonium with Chlorophosphonazo III in n-Pentanol
}

N. M. Saponara

S. F. Marsh 


\title{
SPECTROPHOTOMETRIC DETERMINATION OF PLUTONIUM WITH CHLOROPHOSPHONAZO III IN ID-PENTANOL
}

by

N. M. Saponara and S. F. Marsh

\begin{abstract}
Microgram amounts of plutonium are measured spectrophotometrically as the plutonium-ch!orophosphonazo Ill complex after extraction into n pentanol from $1.5 \mathrm{M}$ $\mathrm{HCl}$. The relative standard deviation is $1.5 \%$ for the range of 2.5 to $17.5 \mu \mathrm{g}$. The tolerance is excellent for many metais and nonjoetals present in nuclear fuel-cycle materials. A preceding anion-exchange column separation increases tolerance for certain metals and nonmetals.
\end{abstract}

\section{INTAODUCTION}

Chlorophosphonazolll(3.6-bis-|(4-chloro-2 phospho nophenyl)azol-4.5-dihydroxy-2.7 naphthalenedisulfonic acid), termed CPA. has been used for spectro photometric determinations of many elements including thorium.' uranium." and plutonium. ${ }^{4}$ The present method has been developed for determining microgram amounts of plutonjum using the Los Alamos automated spectrophotometer or a similar instrument in which all operations. from addition of reagents through the $a b$ sorbance measurements. are done in a single tube. Extraction of the Pu(IV)-CPA complex into a wa ter-immiscible alcohol improves selectivity and simultaneously increases the complex absorbance. A twowavelength absorbance measurement improves precision by correcting for base-line shifts in a single-beam instru. ment. such as the Los Alamos automated spectrophotometer. The method as presented. however. provides a selective determination of plutonium suitable for a manually operated spectrophotometer.

\section{FXPFRIMENTAL}

A. Spectra in Hydrochloric Acid and n-Pentanol

In dilute $\mathrm{HCl}$ solution. plutonium(IV) and CPA form a green complex having absorption peaks at 630 and $685 \mathrm{~nm}$. The peaks of the extracted complex in $n$ pentanol are shifted to shorter wavelengths of 625 and $673 \mathrm{~nm}$ with a four fold increase in absorbance (Fig. 1). similar to the effect reported by Yamamoto for the LiV).CPA complex extracted into 3-methyl-1-butanol. ${ }^{6}$

Various pairs of wavelengths, one wavelength representing the peak and the other the valley. were evaluated for absorbance measurement. The pair giving best precision was 680 and $710 \mathrm{~nm}$

\section{B. Effect of Solvent}

A reliable extraction system requires a solvent that has low viscosity. low volatility. and effective phase dis- 


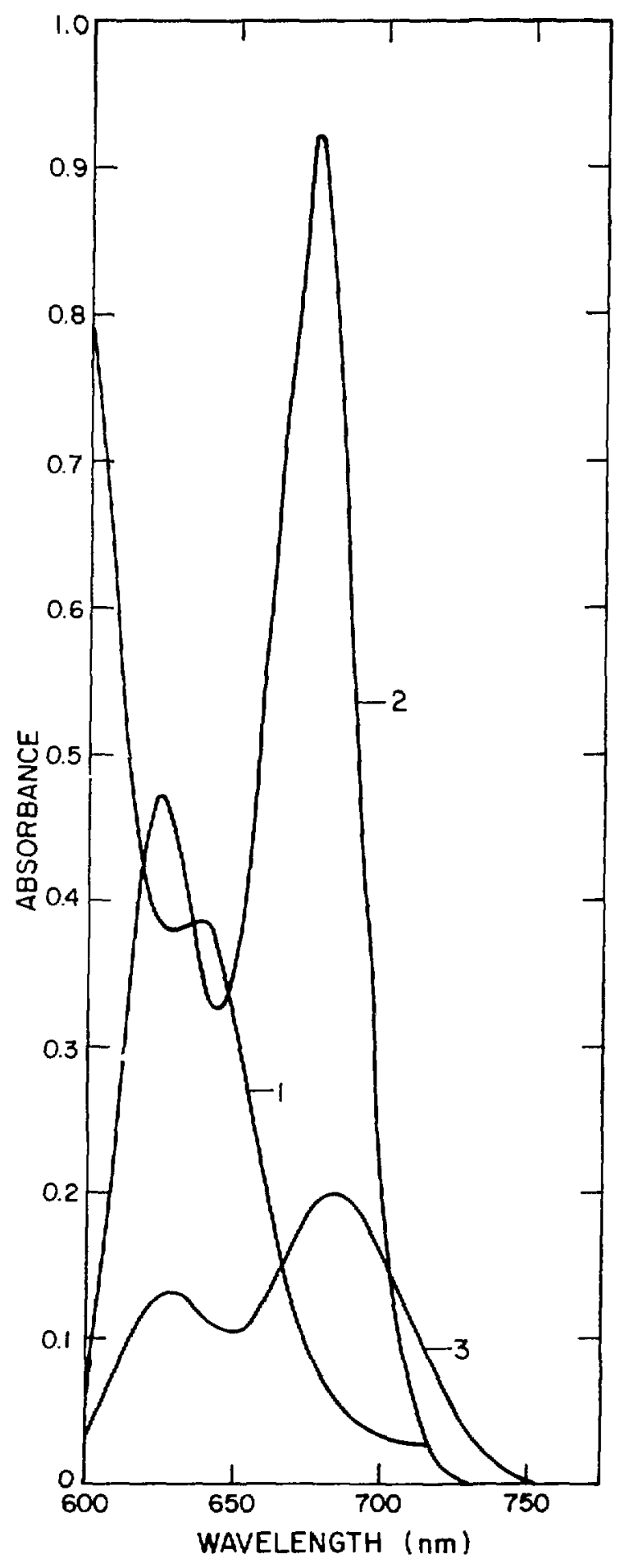

Fig. 1. Absorption Spectra. (1) $0.04 \%$ CPA in n-pentanol relative to air. (2) $15 \mu g$ Pu(IV).CPA in n-pentanol relaxive to reagent blank in n.pentanol. (3) $15 \mu \mathrm{g}$ Pu(IV).CPA in $1.5 \mathrm{M} \mathrm{HCl}$ relative to reagent blank in $1.5 \mathrm{M} \mathrm{HCl}$. engagement. Of five water-immiscible alcohols evaluated, color intensity was higher and phase disengagement better for n-pentanol, isopentanol, and hexanol than for cyclohexanol and p-methylhexanol. $N$-pentanol best met the stated requirements and was selected as the extractant.

\section{Effect of Hydrochloric Acid Concentration}

The absorbance of the Pu(IV)-CPA complex in $n$-pentanol is essentially constant when extracted from 1 to $2 M \mathrm{HCl}$. The solubility of hydrochloric acid in $n$-pentanol increases at higher acid concentrations to lower the absorbance. A concentration of $1.5 \mathrm{M} \mathrm{HCl}$ was selected.

\section{Effect of Plutonium Oxidation State}

The extraction of plutonium, initially in the (III). (IV), and (VI) oxidation states was measured under the conditions of the recommended procedure. The Pu(III) had been prepared by drying the $\mathrm{HI}-\mathrm{HCl}$ eluate from an anion exchange colurnn, $\mathrm{Pu}(\mathrm{JV})$ by oxidizing $\mathrm{Pu}$ (III) with sodium nitrite. and $\mathrm{Pu}(\mathrm{VI})$ by evaporating $\mathrm{Pu}(\mathrm{III})$ to dryness with $\mathrm{HClO}_{4}$ and a trace of $\mathrm{HNO}_{3}$. Extraction was measured in each case by liquid scintillation count. ing the aqueous phase. Extractions of Pu(III) $\mathrm{Pu(IV)}$, and $\mathrm{Pu}(\mathrm{VI})$ were $98.0,99.6$, and $99.4 \%$, respectively, indicating conversion to $\mathrm{Pu}(\mathrm{IV})$, which is strongly complexed by CPA. To ensure constant extraction. sodium nitrite is added in the recommended procedure 10 oxidize Pu(III) to Pu(IV).

\section{E. Effect of Chlorophosphonazo III Concentration}

The effect of CPA concentration on the formation of the complex was established by extracting 10- $\mu \mathrm{g}$ $(0.042 \mu$ mole) portions of $\mathrm{Pu}(\mathrm{IV})$ with increasing quantities of $0.04 \%\left(5.3 \times 10^{-4} \mathrm{M}\right) \mathrm{CPA}$ solution from $1.5 \mathrm{M}$ $\mathrm{HCl}$ into n-pentanol. The absorbance, relative to a reagent blank, increased to $0.6 \mathrm{~m} /$ (0.32 $\mu$ mole) of CPA and was constant thereafter. A volurne of $1 \mathrm{~m} /$ of $0.04 \%(0.53 \mu$ mole $)$ CPA solution was selected.

\section{F. Effect of Time}

The development and extraction of the Pu(IV)-CPA complex is not instantaneous. After $10 \mathrm{~min}$ of phase 
mixing and a 2 -min period of phase disengagement, the absorbance is $93 \%$ of maximum, increasing to $97 \%$ in $2 \mathrm{~h}$ and to the maximum in $12 \mathrm{~h}$. This is not critical for an automated instrument operation in which the timing of all steps is highly reproducible. For manual operation, however. a 2 - $h$ color development time is recommended.

\section{G. Measurement Reliability}

Measurement precision and linearity of absorbance were determined for the range of 0 to $20 \mu \mathrm{g}$ of plutonium. As shown in Table $I$, the response is linear through $17.5 \mathrm{\mu g}$ and the relative standard deviation is better than $1.5 \%$ for the range of 2.5 to $17.5 \mu \mathrm{g}$.

Measurement precision of the method was obtained over a 3-month period. The relative standard deviation for 60 analyses of $10 \mu \mathrm{g}$ of plutonium reference material was $1.7 \%$.

\section{H. Diverse Ion Tolerances}

Diverse ion colerances were established by adding individual ions to $10 \mu \mathrm{g}$ of plutoinium and comparing the absorbances to that of piutonium alone. The initial molar ratio tested was 1000 . If a result was significantly different at the $95 \%$ confidence level relative to plutunium alone. lower amounts were tested until there was no significant difference. The results, summarized in Table 11. show high tolerances for many impurities present in plutonium materials characteristic of the nuclear fucl cycle.

Additional tolerance to diverse ions is difficult to obtain with masking agents because they also form highly stable complexes with $\mathrm{Pu}(\mathrm{IV}){ }^{7}$ Additional selectivity is gained by an ion exchange separation preceding the extraction. described in Sec. I11. Recommended Procedure. The tolerances for selected ions. following the anion exchange separation. are given in Table III.

The anion exchange separation does not lower precision significantly; however. plutonium recovery decreases about $2 \%$. Occasionally a set of samples and reference materials yield low recovery for ai! members of ihe group. This bias is caused by a residue of fine particles or degradation products of the resin that accompanies the eluted plutonium. Wet sieving of the resin to remove fine particles usually eliminates the interference; however, it occasionally recurs. This residue resists oxidative chemical treatments including fuming with perchloric and nitric acids. It can be decomposed by ignition, a treatment not recommended for routine plutonium analyses.

\section{RECOMMENDED PROCEDURE}

\section{A. Reagents}

- Hydrochloric Acid (saturated, 6M. 1.5M). Disti!" $-6 M \mathrm{HCl}$ in a yuartz still. Using polyethylene apparatus, pass $\mathrm{HCl}$ gas into the distilled acid while cooling in an ice bath. Verify that the molarity of the gas saturated hydrochloric acid is at least $12 M$ by titrating with a standard $\mathrm{NaOH}$ solution. Dilute as necessary with distilled water to obtain $6 M$ and $1.5 \mathrm{M} \mathrm{HCl}$.

- Hydriodic Acid Hydrochloric Acid Mixture (0.1M $\mathrm{HI}(2 . \mathrm{M} \mathrm{HCl})$. Dilute $1 \mathrm{~m} /$ distilled $7.4 \mathrm{M} \mathrm{HI}$ to $74 \mathrm{~m}$ e with saturated $\mathrm{HCl}$. Prepare this reagent fresh before use. The $\mathrm{HI}$ is distilled. preferably in quariz apparatus. to remove $\mathrm{H}_{3} \mathrm{PO}_{2}$. the holding reductant in AR grade HI. Store the distilled $\mathrm{HI}$ in flame-sealed ampoules or in plastic containers under inert atmosphere.

- Nitric Acid (15.6. W). Use quartz-distilled $\mathrm{HNO}_{3}$.

- Perchloric Acid (6M). Mix $50 \mathrm{~m} / 12 \mathrm{M} \mathrm{HClO}$ with $50 \mathrm{~m}$ / distilled water.

- Anion Exchange Resin. Bio-Rad AG MP.1, 50100 mesh. chloride form. Separate the fines by backwashing with distilled water.

- Chlorophosphonazo III $(0.04 \%$ solution in $0.5 \mathrm{M}$ $\mathrm{HCl}$. ICN Pharmaceuticals. Inc., Plainview, NY 11803. Dissolve $40 \mathrm{mg}$ CPA in a $100 \mathrm{~m} / \mathrm{vol}$ umetric hask using $96 \mathrm{~m} t$ distilled water and $4 \mathrm{~m} t$ $12 \mathrm{M} \mathrm{HCl}$. This solution is stable in the absence of strong oxidizing or reducing agents.

- n-Pentanol. Kodak Laboratory Chemicals, Rochester. NY 14650. Use without further purification.

- Sodium Nitrite $(1 M)$. Dissolve $6.9 \mathrm{~g}$ of the reagent in $100 \mathrm{mr}$ distilled water. 
TABLE I. Linearity of Absorbance and Measuremient Precision"

\begin{tabular}{|c|c|c|c|}
\hline $\begin{array}{c}\text { Plutonium } \\
(\mu \mathrm{g})\end{array}$ & Absorbance & $\begin{array}{c}\text { Absorbance } \\
\text { Relative to } \\
\text { Reagent Blank } \\
\text { per } \\
\mu \mathrm{g} \text { Plutonium }\end{array}$ & $\begin{array}{c}\text { Rel. Std. Dev. } \\
(\%)\end{array}$ \\
\hline 0. & 0.037 & 0.000 & 11.4 \\
\hline 1. & 0.091 & 0.054 & 2.8 \\
\hline 2.5 & 0.170 & 0.053 & 0.7 \\
\hline 5. & 0.310 & 0.055 & 1.5 \\
\hline 7.5 & 0.439 & 0.054 & 1.0 \\
\hline 10. & 0.579 & 0.054 & 0.7 \\
\hline 12.5 & 0.709 & 0.054 & 1.4 \\
\hline 15. & 0.842 & 0.054 & 0.8 \\
\hline 17.5 & 0.962 & 0.053 & 0.5 \\
\hline 20. & 1.056 & 0.051 & 2.0 \\
\hline
\end{tabular}

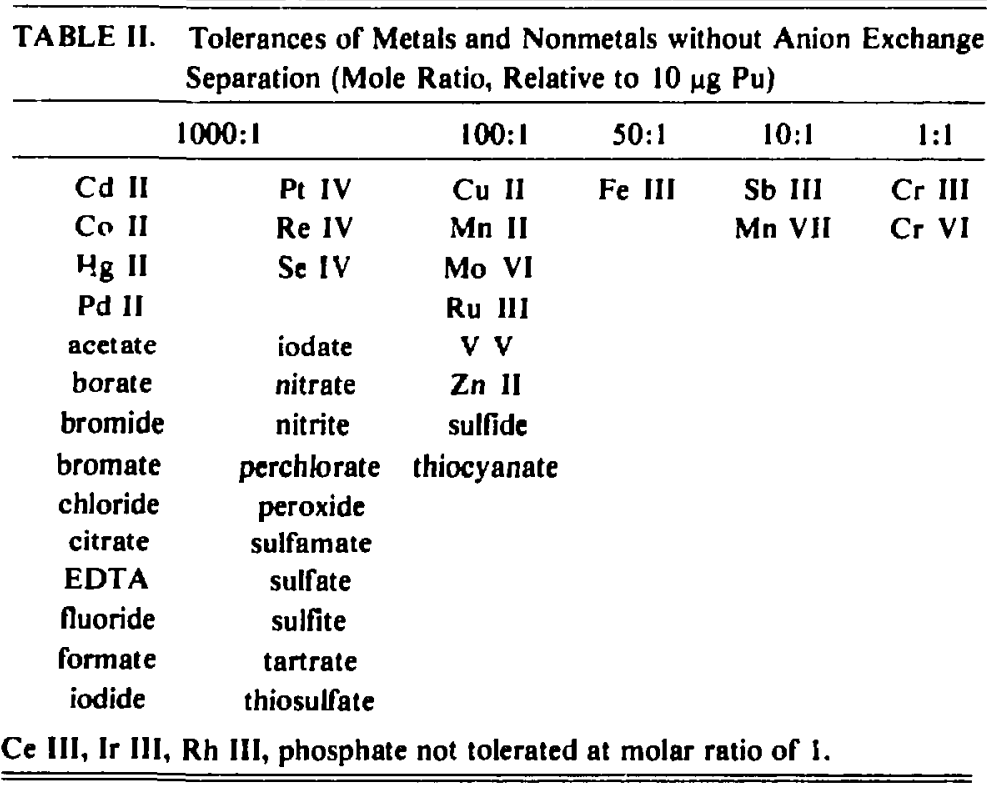




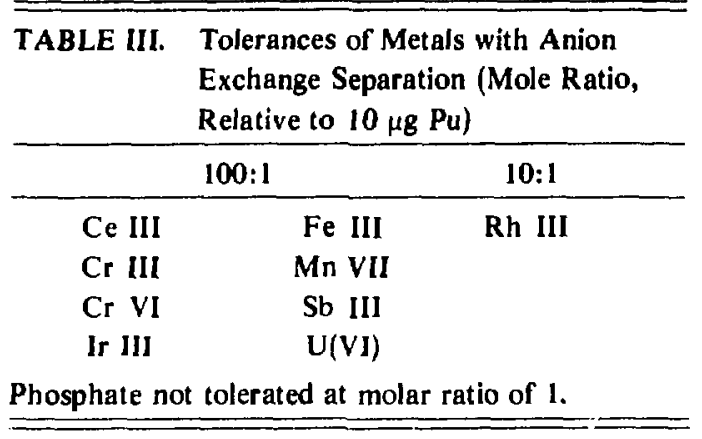

B. Apparatus

- A double-beam recording spectrophotometer with $1-\mathrm{cm}$ cells was used for absorbance measurements.

- An inversion rolator, $48 \mathrm{rpm}$, Scientific Industries. Inc., Springfield, MA 01103 , was used for extracting the Pu(IV)-CPA complex into pentanol.

\section{Ion Exchange Separation (optional)}

1. Column Preparation. Prepare he columns from disposable $1.6 \mathrm{~m} /$ polyethylene droptiers having $2 \mathrm{~m} t$ reservoirs (Cole-Parmer Instrument Co., Chicago, Il 60648 , No. C 6096.00 or equivalent). Cut off the top of the dropper to form an open reservoir and insert a small wad of quartz wool in the tip. Transfer a water slurry of the ion exchange resin into the column until the settled height is just below the reservoir. Immediately before use, pass $6 \mathrm{~m} /$ of the specially prepared, saturated $\mathrm{IICl}$ through the column. Keep the column wet with saturated $\mathrm{HCl}$ until use.

\section{Column Separation.}

(a) To an aliquot containing between 1 and $17.5 \mu \mathrm{g}$ of plutonium in a $10-\mathrm{m} /$ Teflon $x$ beaker, add 2 drops of $6 M \mathrm{HClO}_{4}$ and 1 drop of concentrated $\mathrm{HNO}_{3}$, then evaporate to dryness.

- All Pu(III) oxidizes.

(b) Dissolve and transfer the residue with a polyethylene dropper to the anion exchange column with three $0.5-\mathrm{m} /$ portions of saturated $\mathrm{HCl}$.

- Americium. thorium, and many interfering elements elute.

(c) Pass $8 \mathrm{~m} /$ saturated $\mathrm{HCl}$ through the column in

\section{$2-\mathrm{m} /$ increments.}

- This completes the elution of many interfering elements.

(d) Place a $15-\mathrm{m} /$ glass test tube under the column and elute the plutonium fraction with two $2-\mathrm{m} /$ portions of $0.1 \mathrm{M} \mathrm{HCl}$ mixture, then wait $10 \mathrm{~min}$.

- Plutonium reduces to Pu(III).

(e) Pass four 2-m/ portions of the $0.1 M \mathrm{HI}-12 \mathrm{M} \mathrm{HCl}$ mixture through the column to complete the reduction and quantitative elution of plutonium.

(I) After allowing the saturated $\mathrm{HCl}$ eluate from step (e) to outgas overnight, gently evaporate the solution to dryness.

(g) Add one drop of concentrated $\mathrm{HNO}_{3}$ to the residue and heat to remove the residual $\mathrm{HI}$.

(h) Convert the residue to a chloride salt by heating to dryness with one drop of $6 \mathrm{M} \mathrm{HCl}$.

(i) Redissolve the salt in $4 \mathrm{mf}$ of $1.5 \mathrm{M} \mathrm{HCl}$.

\section{Extraction and Absorbance Measurement}

- Using the recommended procedure and standard reference material. establish a calibration curve in the range of 0 to $17.5 \mu \mathrm{g}$ of plutonium.

1. Deliver a 4-m/ aliquot containing between I and $17.5 \mu \mathrm{g}$ of plutonium in $1.5 \mathrm{M} \mathrm{HCl}$ into a glass test tube.

2. Add $0.1 \mathrm{~m} / 1 M \mathrm{NaNO}_{2}$ and u'arm the solution in a $60^{\circ} \mathrm{C}$ water bath for $10 \mathrm{~min}$.

- Pu(III) oxidizes to Pu(IV').

3. After cooling, add $1 \mathrm{~m} / 0.04 \%$ CPA solution and briefly agitate the mixture.

- Pu(IV).CPA complex forms.

4. Add $10 \mathrm{~m} / \mathrm{n}$-pentanol. Seal the test tube with a hollow polyethylene stopper using masking tape and mix the two phases for $10 \mathrm{~min}$ using a 48-rpm inversion rotator.

- Pu(IV)-CPA complex extracts into n-pentanol.

5. After phase disengagement, measure absorbance at 680 and $710 \mathrm{~nm}$. For manual operation, a 2-h wait is recommended before absorbance measurement.

- The difference, between the two absorbance measurements is proportional to the plutonium concentration.

\section{ACKNOWLEDGMENTS}

Technical guidance and editorial suggestions of J. E. Rein are appreciated. 


\section{REFERENCES}

1. T, Yamamoto, "Extraction-Photometric Determination of Thorium with Chlorophosphonazo Ill," Anal. Chim. Acta 63, 65-70 (1973).

2. V. F. Luk'yanov, A. M. Lukin, E. P. Duderova, and T. E. Barabanova, "Photometric Determination of the Uranyl Ion by Means of Phosphonazo III and Chlorophosphonazo IIl in Strongly Acid Solutions," Zh. Anal. Khim. 26, No. 4, 772-776 (April 1971).

3. T. T. Bykhovtsova and I. A. Tserkovnitskaya, "Photometric Determination of Uranium VI by Means of Chlorophosphonazo III in Organic Solutions after the Extraction Separation of Uranium by Means of Trialkylamines," $\mathrm{Zh}$. Anal. Khim. 32, No. 4, 745-750 (Anril 1977).
4. T. Yamamoto, "Spectrophotometric Determination of Plutonium with Chlorophosphonazo III," Mikrochim. Acta 871-877 (1974).

5. D. D. Jackson, D. J. Hodgkins, R. M. Hollen, J. E. Rein, "Automated Spectrophotometer for Plutonium and Uranium Determination," Los Alamos Scientific Laboratory report LA-6091 (February 1976).

6. T. Yamamoto, "Extraction-Photometric Determination of Uranium IV with Chlorophosphonazo III," Anal. Chim. Acta 65, 329.334 (1973).

7. F. W. E. Strelow and T. N. Van der Wart, "Comparative Study of the Masking Effect of Various Complexans in the Spectrophotometric Determination of Uranium with Arsenazo 111 and Chlorophosphonazo III," Talanta 26, 537-542 (1979). 